FERNÁNDEZ, Dora García. La violencia al inicio de la vida: una perspectiva bioética y de los derechos humanos. Revista Eletrônica Direito e Política, Programa de Pós-Graduação Stricto Sensu em Ciência Jurídica da UNIVALI, Itajaí, v.11, n.2, 2으 quadrimestre de 2016. Disponível em: www.univali.br/direitoepolitica - ISSN 1980-7791.

\title{
LA VIOLENCIA AL INICIO DE LA VIDA: UNA PERSPECTIVA BIOÉTICA Y DE LOS DERECHOS HUMANOS
}

\author{
THE VIOLENCE AT THE BEGINNING OF LIFE: \\ A BIOETHIC PERSPECTIVE AND IN HUMAN RIGHTS
}

\section{Dora García Fernández ${ }^{1}$}

SUMARIO: Introducción. 1. Teorías sobre el origen de la violencia en el ser humano. 2. Bioética y Derechos Humanos. 3. La violencia en el inicio de la vida. 3.1. Maltrato fetal 3.2. Aborto 3.3. Investigación con embriones 3.4. Congelación de embriones. Consideraciones finales. Referencias bibliográficas

\section{RESUMEN}

Violencia es actuar fuera de su natural estado, es ejecutar con fuerza, ímpetu o brusquedad o algo que se hace contra el gusto o la voluntad de uno mismo. El fenómeno de la violencia siempre ha afligido a la humanidad como lo demuestra la historia. Actualmente, como fenómeno global, se considera por muchos como un problema de salud pública, debido a las múltiples causas que la producen se dificulta la percepción de su dimensión real.

Desde la perspectiva de la Bioética se interpreta la violencia como una forma de relación humana donde existe el deseo de hacer mal, lesionando la autonomía del otro, donde se vulneran los principios bioéticos universales. Así también se considera la violencia una forma de inequidad o falta de justicia, cuando se quebrantan los derechos humanos y se atenta contra la vida y la dignidad de la persona humana. En esta investigación se quiere comprobar que la violencia existe desde el inicio de la vida, porque es justamente ahí donde comienza el problema de los abusos, malos tratos y violencia contra el ser humano no nacido.

\footnotetext{
1 Profesora investigadora del Instituto de Investigaciones Jurídicas de la Universidad Anáhuac México, Campus Norte, Directora editorial de la Revista Iuris Tantum y miembro del Sistema Nacional de Investigadores del CONACYT, México. dgarcia@anahuac.mx
} 
FERNÁNDEZ, Dora García. La violencia al inicio de la vida: una perspectiva bioética y de los derechos humanos. Revista Eletrônica Direito e Política, Programa de Pós-Graduação Stricto Sensu em Ciência Jurídica da UNIVALI, Itajaí, v.11, n.2, 2으 quadrimestre de 2016. Disponível em: www.univali.br/direitoepolitica - ISSN 1980-7791.

PALABRAS CALVE: Salud pública, conducta humana, violencia, bioética, derechos humanos, no nacido

\section{ABSTRACT}

Violence is acting outside its natural state, is to execute with force, strength or chattering or something that is being done against soemone's will. The phenomenon of violence has always afflicted humanity as evidenced by history. Currently, as a global phenomenon, is considered by many as a public health problem, due to the multiple causes that the produce it, it's difficult the perception of its real dimensions. From the perspective of Bioethics violence is interpreted as a form of human relationship where there is the desire to do evil, violating the autonomy of the other, and violate the universal bioethical principles. It also considers the violence an inequity or lack of justice, when human rights are violated and assault the life and the dignity of the human person. In this research we want to verify that the violence exists since the beginning of life, because it is precisely there where begins the problem of abuse, ill-treatment and violence against the unborn human being.

KEY WORDS: Public health, human behavior, violence injuries, bioethics, human rights, unborn

\section{INTRODUCCIÓN}

Violencia, proviene del latín violentǐa, es la cualidad de violento o la acción y efecto de violentar o violentarse. Lo violento, por su parte, es aquello que está fuera de su natural estado, situación o modo; que se ejecuta con fuerza, ímpetu o brusquedad; o que se hace contra el gusto o la voluntad de uno mismo. ${ }^{2}$

2 Violencia, en http://Definición de violencia - Qué es, Significado y Concepto http://definicion.de/violencia/\#ixzz4CR5TPcym, fecha de consulta 23 de junio de 2016. 
FERNÁNDEZ, Dora García. La violencia al inicio de la vida: una perspectiva bioética y de los derechos humanos. Revista Eletrônica Direito e Política, Programa de Pós-Graduação Stricto Sensu em Ciência Jurídica da UNIVALI, Itajaí, v.11, n.2, 2으 quadrimestre de 2016. Disponível em: www.univali.br/direitoepolitica - ISSN 1980-7791.

Afirma el fislósofo español José Luis López Aranguren que la violencia como tal solo existe en el hombre. El animal posee agresividad, pero no ejerce actos de violencia propiamente dicha. $Y$ su agresividad está limitada a hacerse con su presa para el sustento, a la defensa de su territorio $y$, dentro de la especie, al establecimiento de una jerarquización u orden de relación para el apareamiento. ${ }^{3}$

Desde esta perspectiva se interpreta la violencia como una forma de relación humana donde existe el deseo de hacer mal, lesionando la autonomía del otro y donde se vulneran los principios bioéticos universales. Así también se considera la violencia una forma de inequidad o falta de justicia, cuando se quebrantan los derechos humanos y se atenta contra la vida y la dignidad de la persona humana.

La Bioética en sí misma es una lucha contra la violencia ejercida al no nacido y al ser humano a partir de su personalidad jurídica (nacimiento), con la constante violación de sus derechos humanos.

La Bioética personalista vinculada estrechamente con la normatividad ética, y desde luego, jurídica, es la que regula los aspectos esenciales de la persona humana en todas las etapas de su vida, y por supuesto, con el respeto absoluto de sus derechos esenciales o derechos humanos fundamentales. Dicho en otras palabras, la Bioética funge como

3 BASSOLS, Ramón. Las raíces psicológicas de la violencia. en http://www.temasdepsicoanalisis.org/wp-content/uploads/2012/06/TdP-N\%C2\%BA-4R. Bassols1.pdf, fecha de consulta: 24 de junio de 2016. 
FERNÁNDEZ, Dora García. La violencia al inicio de la vida: una perspectiva bioética y de los derechos humanos. Revista Eletrônica Direito e Política, Programa de Pós-Graduação Stricto Sensu em Ciência Jurídica da UNIVALI, Itajaí, v.11, n.2, 2으 quadrimestre de 2016. Disponível em: www.univali.br/direitoepolitica - ISSN 1980-7791.

defensora del ser humano ante la violencia que se puede ejercer contra de él.

\section{TEORÍAs SOBRE EL ORIGEN DE LA VIOLENCIA EN EL SER HUMANO}

¿De dónde proviene la violencia en el ser humano? La violencia, según Víctor Montoya, existe desde siempre. Violencia para sobrevivir, violencia para controlar el poder, violencia para sublevarse contra la dominación, violencia física y psíquica.

Para Nicolás Maquiavelo y para Friedrich Nietzsche, la violencia es algo inherente al género humano. ${ }^{4}$

Pero sobre el origen de la violencia existen varias teorías entre ellas:

Las Teorías activas o innatistas, que son las que suponen que el origen de la agresión se encuentra en los impulsos internos de la persona. Dentro de este grupo de teorías están:

- Teoría etológica, que estudia las causas del comportamiento animal extrapoladas a la conducta humana. Considera que la agresión es una acción innata que se basa en impulsos inconscientes y que se han ido adaptando con la evolución de la especie. La finalidad de la violencia es la supervivencia de la persona y de su especie.

\footnotetext{
${ }^{4}$ MONTOYA, Víctor, Teorías de la violencia humana. en http://www.razonypalabra.org.mx/anteriores/n53/vmontoya.html, fecha de consulta: 29de junio de 2016.
} 
FERNÁNDEZ, Dora García. La violencia al inicio de la vida: una perspectiva bioética y de los derechos humanos. Revista Eletrônica Direito e Política, Programa de Pós-Graduação Stricto Sensu em Ciência Jurídica da UNIVALI, Itajaí, v.11, n.2, 2o quadrimestre de 2016 . Disponível em: www.univali.br/direitoepolitica - ISSN 1980-7791.

- Teoría psicoanalítica, Sostiene que la agresividad es un componente instintivo básico que surge como reacción ante el bloqueo de la libido, es decir, ante el bloqueo o impedimento de la consecución de aquello que provoca placer. Si la persona es capaz de liberar la tensión interior acumulada por el bloqueo de la libido se producirá un estado de relajación, pero si no es capaz de liberarla, surgirá la agresión. Por lo tanto, para esta teoría, la violencia es un cúmulo de afectos negativos internos que la persona no puede exteriorizar.

- Teoría de la personalidad, supone que el comportamiento violento de un individuo es debido a rasgos de su personalidad, es decir, los factores de la personalidad aumentan la probabilidad de que una persona sea violenta o agresiva.

- Teoría de la frustración ${ }^{5}$, considera que todo comportamiento agresivo es a consecuencia de alguna frustración previa. Es decir, la frustración del incumplimiento de una meta está directamente relacionada con la violencia.

- Teoría de la señal activación ${ }^{6}$, que explica el fenómeno de la agresión a partir de los supuestos de la teoría de la frustración pero

\footnotetext{
5 Propuesta por los psicólogos John Dollar y Neal Miller en 1938.

${ }^{6}$ Propuesta por Berkowitz (1969).
} 
FERNÁNDEZ, Dora García. La violencia al inicio de la vida: una perspectiva bioética y de los derechos humanos. Revista Eletrônica Direito e Política, Programa de Pós-Graduação Stricto Sensu em Ciência Jurídica da UNIVALI, Itajaí, v.11, n.2, 2으 quadrimestre de 2016. Disponível em: www.univali.br/direitoepolitica - ISSN 1980-7791.

con ciertas modificaciones. En esta teoría la frustración no provoca directamente la agresión sino que surge a través de la ira. La frustración provoca ira y la ira activa al organismo para la agresión, que finalmente se puede producir dependiendo del grado emocional de la persona. ${ }^{7}$

- Teoría genética, sostiene que las agresiones son resultado de síndromes patológicos orgánicos (por ejemplo alguna anomalía cromosómica) o de procesos bioquímicos y hormonales que tienen lugar en el organismo. Le da mucha importancia a la predisposición genética y a los aspectos hereditarios en el desarrollo de las conductas agresivas y violentas en una persona.

El otro grupo es el de las Teorías reactivas o ambientales, que suponen que el origen de la violencia se encuentra en el medio ambiente que rodea a la persona, de tal forma que la agresión es una reacción de emergencia frente a los sucesos ambientales o a la sociedad en su conjunto. Entre estas teorías están:

- Teoría del aprendizaje social, considera que el comportamiento agresivo es el resultado de un aprendizaje por observación e imitación y la imitación de la conducta violenta dependerá de si obtiene un beneficio o un castigo.

7 Cfr. Teorías sobre el origen de la violencia. en http://derechobullying.jimdo.com/t\%C3\%A9cnicas-de-investigaci\%C3\%B3n/marcote\%C3\%B3rico/teorias-sobre-el-origen-de-la-violencia/, fecha de consulta: 29 de junio de 2016. 
FERNÁNDEZ, Dora García. La violencia al inicio de la vida: una perspectiva bioética y de los derechos humanos. Revista Eletrônica Direito e Política, Programa de Pós-Graduação Stricto Sensu em Ciência Jurídica da UNIVALI, Itajaí, v.11, n.2, 2o quadrimestre de 2016 . Disponível em: www.univali.br/direitoepolitica - ISSN 1980-7791.

- Teoría de la interacción social, supone que la conducta del individuo depende principalmente de la influencia del ambiente y del contexto social donde se desarrolla. Esta interacción tiene un carácter bidireccional, es decir, el ambiente influye a la persona y la persona al ambiente.

- Teoría sociológica, que interpreta la violencia como un producto de las características culturales, políticas y económicas de la sociedad. Factores como la pobreza, la marginación, la dificultad del desarrollo intelectual, la explotación o el sometimiento a sistemas altamente competitivos, son la principal causa de los problemas de conducta en las personas. Esta teoría también da gran importancia a los valores predominantes en la sociedad. ${ }^{8}$

Todas estas teorías sobre el carácter innato o adquirido de la violencia en el ser humano han llevado a grandes discusiones sobre el verdadero origen de la violencia y aún no se ha llegado a una conclusión determinante.

\section{BIOÉTICA Y DERECHOS HUMANOS}

\footnotetext{
${ }^{8} \mathrm{Cfr}$. Teorías sobre el origen de la violencia. en http://derechobullying.jimdo.com/t\%C3\%A9cnicas-de-investigaci\%C3\%B3n/marcote\%C3\%B3rico/teorias-sobre-el-origen-de-la-violencia/, fecha de consulta: 29 de junio de 2016.
} 
FERNÁNDEZ, Dora García. La violencia al inicio de la vida: una perspectiva bioética y de los derechos humanos. Revista Eletrônica Direito e Política, Programa de Pós-Graduação Stricto Sensu em Ciência Jurídica da UNIVALI, Itajaí, v.11, n.2, 2으 quadrimestre de 2016. Disponível em: www.univali.br/direitoepolitica - ISSN 1980-7791.

En 1978 se define por primera vez el término Bioética como: "El estudio sistemático de la conducta humana en el campo de la ciencia de la vida y la salud, analizada a la luz de los valores y principios morales". Pero se puede resumir diciendo que la Bioética es la ética aplicada a todos los aspectos de la vida.

Para el padre Ramón Lucas Lucas la Bioética es humana, porque concierne directamente a la vida y a la salud de las personas, e indirectamente a su entorno; es racional, porque se rige por los valores morales basados en la dignidad humana; es universal, porque es válida para toda la humanidad sin distinción de raza o credo y es interdisciplinaria, porque en ella convergen disciplinas como las Ciencias de la Salud, el Derecho, la Filosofía, la Biología, la Ecología, etc. ${ }^{9}$

Tres son los principios fundamentales que rigen a la Bioética:

10 Principio de beneficencia. Que consiste en promover el bien del paciente y evitar el mal: primum non nocere (Ante todo no dañar y por lo tanto, no ejerce violencia en contra del otro).

20 Principio de autonomía. Se refiere al respeto de los derechos fundamentales del hombre, el respeto a la persona humana. "No hacer a los demás lo que no quieras que te hagan a ti".

$3^{\circ}$ Principio de justicia. Dar a cada quien lo que le corresponde. Se trata de la distribución equitativa de los recursos para prestar los servicios de

\footnotetext{
${ }^{9}$ LUCAS LUCAS, R., (2008) Bioética para todos. 3a ed., Trillas, México, págs. 7 y 8.
} 
FERNÁNDEZ, Dora García. La violencia al inicio de la vida: una perspectiva bioética y de los derechos humanos. Revista Eletrônica Direito e Política, Programa de Pós-Graduação Stricto Sensu em Ciência Jurídica da UNIVALI, Itajaí, v.11, n.2, 2으 quadrimestre de 2016. Disponível em: www.univali.br/direitoepolitica - ISSN 1980-7791.

salud, para la investigación, etc. El respeto a la vida y a la proporcionalidad de las actuaciones. . ${ }^{10}$

Estos principios de la Bioética se equiparan a los principios establecidos por Santo Tomás de Aquino: "Se debe obrar persiguiendo el bien y evitando el mal", por San Agustín y Kant: "No hagas lo que no quieras que te hagan" y por Ulpiano: "Vivir honestamente, dar a cada quien lo suyo y no hacer daño a otros".

En la Bioética influyen cuatro corrientes filosóficas, a saber:

\section{Naturalismo sociobiologista}

Establece que la vida y la sociedad están sujetas a la evolución biológica y sociológica. Propone una ética basada en el evolucionismo. En esta corriente se cree que es suficiente describir y observar empíricamente los comportamientos de un grupo social para extraer de ahí normas de conducta para la colectividad. " "Así es = Así debe ser".

2. Liberal radical o subjetivista

Los juicios sólo pueden ser medidos con los hechos y es imposible pasar de los hechos a los valores y normas éticas. Es subjetivista porque los hechos son originados únicamente por el sujeto. En este modelo no existe

10 SGReCCIA, E. (2009) Manual de Bioética, Biblioteca de Autores Cristianos. Madrid. pág. 164. 
FERNÁNDEZ, Dora García. La violencia al inicio de la vida: una perspectiva bioética y de los derechos humanos. Revista Eletrônica Direito e Política, Programa de Pós-Graduação Stricto Sensu em Ciência Jurídica da UNIVALI, Itajaí, v.11, n.2, 2으 quadrimestre de 2016. Disponível em: www.univali.br/direitoepolitica - ISSN 1980-7791.

una verdad o un bien universal, la libertad y la autodeterminación del individuo son fundamento de sus elecciones morales. ${ }^{11}$

\section{Pragmático utilitarista}

Propone la utilidad social como valor supremo en la jerarquía de valores. Prevalecen los intereses de la mayoría sobre los del individuo. La elección moral se hará en base a la obtención del mayor bienestar para el mayor número posible de individuos. En este modelo de pensamiento se toma en cuenta el parámetro costo-beneficio como referencia en la toma de una decisión ética. ${ }^{12}$

\section{Personalista}

Esta corriente filosófica considera que el principio fundamental de la Bioética es la dignidad de la persona humana. El valor primario es la vida y exige el ejercicio responsable de la libertad. Toma como centro a la persona humana, acepta su indivisibilidad y unidad física, síquica y espiritual desde el momento de la concepción hasta la muerte. La ley natural es el criterio de referencia para determinar si un acto es bueno o malo, si es verdadero o falso en el ámbito moral. Asimismo, el personalismo reconoce la importancia de respetar a los seres animales y vegetales, aunque subordinándolo al bien de la persona humana. ${ }^{13}$

11 Siendo que la vida es lo que da fundamento a la libertad, ya que sin vida no hay libertad. Cfr. SGRECCIA, E. (2009) Manual de Bioética, Biblioteca de Autores Cristianos. págs. 28 y 29.

12 SGReCCIA, E. (2009) Manual de Bioética, Biblioteca de Autores Cristianos. págs. 30 y 31 .

13 SGRECCIA, E. (2009) Manual de Bioética, Biblioteca de Autores Cristianos. págs. 32 y 33. 
FERNÁNDEZ, Dora García. La violencia al inicio de la vida: una perspectiva bioética y de los derechos humanos. Revista Eletrônica Direito e Política, Programa de Pós-Graduação Stricto Sensu em Ciência Jurídica da UNIVALI, Itajaí, v.11, n.2, 2으 quadrimestre de 2016. Disponível em: www.univali.br/direitoepolitica - ISSN 1980-7791.

Este modelo se basa en cinco principios:

10 El valor fundamental de la vida. Suprimir la vida es privar a la persona humana de su bien fundamental.

20 El principio de corporeidad. La persona humana recibe en el cuerpo su individualidad y diferenciación. El médico, a través del cuerpo del paciente actúa sobre su corporeidad y con este acto interviene en la totalidad de la persona, y no sólo actúa ante una parte o un órgano.

30 El principio de libertad y responsabilidad. La persona es responsable, ante todo, de su propio cuerpo. La ética del médico se basa en el consentimiento del paciente y en la relación de alianza médicopaciente. El médico no debe actuar sino respetando la libertad de su paciente, quien tiene que ser responsable de su corporeidad como un valor objetivo y no como un objeto disponible. Asimismo, el médico es una persona libre y responsable que debe prestar un servicio calificado y profesional y de ninguna manera puede ser reducido a un instrumento de la voluntad del paciente. El médico es responsable del bienestar de su paciente quien por su libre elección le ha confiado al médico su curación.

40 El principio terapéutico. Propone que es lícito intervenir sobre el cuerpo de una persona, después de otorgar su consentimiento, siempre y cuando exista una justificación terapéutica, es decir, la intervención de la "parte" beneficia al "todo".

50 El principio de sociabilidad-subsidiaridad. Implica la necesidad que tiene una persona de ayudarse mutuamente con otras personas pero reconociéndose entre sí la misma dignidad para todos. Como ejemplo de 
FERNÁNDEZ, Dora García. La violencia al inicio de la vida: una perspectiva bioética y de los derechos humanos. Revista Eletrônica Direito e Política, Programa de Pós-Graduação Stricto Sensu em Ciência Jurídica da UNIVALI, Itajaí, v.11, n.2, 2으 quadrimestre de 2016. Disponível em: www.univali.br/direitoepolitica - ISSN 1980-7791.

este principio tenemos la donación de órganos, que se complementa con el principio terapéutico también. ${ }^{14}$

Ahora bien, los Derechos Humanos se definen como aquellas libertades y facultades relativas a bienes primarios o básicos que son inherentes a toda persona, por su condición de ser humano, para la garantía de una vida digna, es decir, son derechos que corresponden a todos los seres humanos, por el simple hecho de serlo, sin distinción de raza, sexo, religión, lengua o cualquier otra condición. ${ }^{15}$ Estos derechos están contemplados en la ley y son garantizados por ella.

Los Derechos Humanos se ven plasmados en constituciones, tratados internacionales y otros ordenamientos jurídicos, es así que las declaraciones de los derechos humanos son consideradas un gran logro de la humanidad, pero la violación masiva de estos derechos continúa siendo la realidad latente en varios países del mundo, en especial, en los países con alta pobreza.

El médico bioeticista Ricardo Páez Moreno afirma que el respeto a los Derechos Humanos en el campo de la Bioética es un asunto que adquiere cada vez más importancia en el mundo globalizado, dado que los mínimos de dignidad humana son global y crecientemente infringidos para grandes colectivos, situación que atenta contra sus derechos humanos más

\footnotetext{
14 SGRECCIA, E. (2009) Manual de Bioética, Biblioteca de Autores Cristianos. págs. 33 a 35 .
}

\footnotetext{
${ }^{15}$ Declaración Universal de los Derechos Humanos, en http://www.un.org/es/documents/udhr/
}

Fecha de consulta: 29 de junio de 2016. 
FERNÁNDEZ, Dora García. La violencia al inicio de la vida: una perspectiva bioética y de los derechos humanos. Revista Eletrônica Direito e Política, Programa de Pós-Graduação Stricto Sensu em Ciência Jurídica da UNIVALI, Itajaí, v.11, n.2, 2으 quadrimestre de 2016. Disponível em: www.univali.br/direitoepolitica - ISSN 1980-7791.

elementales, como son el derecho a la vida, a la salud, a decidir su vida reproductivo-sexual, a la asistencia sanitaria, a proteger sus riquezas naturales como la biodiversidad, a la paridad de género. Opina que la práctica biomédica en los países pobres requiere ser abordada por evaluación bioética propia, la cual no puede dejar a un lado el gran reto que constituyen los Derechos Humanos. ${ }^{16}$

Los Derechos Humanos se consideran un gran triunfo del hombre y son el paradigma ético y jurídico de nuestros tiempos. La Bioética se basa en gran medida, en estos derechos, los cuales sirven de guía para la toma de decisiones y acciones. Para la doctora Juliana González, los derechos humanos son las bases jurídicas y el mínimo ético irrenunciable sobre las que deben asentarse las sociedades occidentales. ${ }^{17}$

En este tenor, el 19 de octubre de 2005, en Paris, la Conferencia General de la UNESCO en su 33a reunión adoptó la Declaración Universal sobre Bioética y Derechos Humanos. Esta Declaración propone la instauración internacional de principios comunes respecto a las cuestiones éticas relacionadas con la medicina, las ciencias de la vida y las tecnologías aplicadas a los seres humanos, teniendo en cuenta sus dimensiones sociales, jurídicas y ambientales. Los objetivos de esta Declaración establecidos en el Artículo $2^{\circ}$ son varios pero el más importante es:

${ }^{16} \mathrm{Cfr}$. PÁEZ MORENO, R. Los derechos humanos y la Bioética: una perspectiva desde Latinoamérica. en fecha http://www.bioetica.unam.mx/assets/ricardopaez.pdf, fecha de consulta: 20 de junio de 2016.

${ }^{17}$ Cfr. GONZÁLEZ, J., Genoma humano y dignidad humana, en RICARDO PÁEZ MORENO, Los derechos humanos y la Bioética: una perspectiva desde Latinoamérica. en http://www.bioetica.unam.mx/assets/ricardo-paez.pdf , fecha de consulta: 20 de junio de 2016. 
FERNÁNDEZ, Dora García. La violencia al inicio de la vida: una perspectiva bioética y de los derechos humanos. Revista Eletrônica Direito e Política, Programa de Pós-Graduação Stricto Sensu em Ciência Jurídica da UNIVALI, Itajaí, v.11, n.2, 2으 quadrimestre de 2016. Disponível em: www.univali.br/direitoepolitica - ISSN 1980-7791.

"Promover el respeto de la dignidad humana y proteger los derechos humanos, velando por el respeto de la vida de los seres humanos y las libertades fundamentales, de conformidad con el derecho internacional relativo a los derechos humanos". 18

Este importante instrumento contempla principalmente aspectos bioéticos relacionados con la justicia, el respeto a la dignidad humana y a los derechos humanos. Se inserta en una postura de respeto a la pluralidad $y$, a la vez, propugna que la comunidad internacional "establezca principios universales que sirvan de fundamento para una respuesta de la humanidad a los dilemas y controversias cada vez numerosos que la ciencia y la tecnología plantean a la especie humana y al medio ambiente". ${ }^{19}$

Es interesante, por tanto, señalar que el primer principio promulgado en este instrumento en su Artículo $3^{\circ}$ es que se habrán de respetar plenamente la dignidad humana, los derechos humanos y las libertades fundamentales, asimismo, los intereses y el bienestar de la persona deberán tener prioridad con respecto al interés exclusivo de la ciencia o la sociedad. 20

18 Declaración Universal sobre Bioética y Derechos Humanos adoptada por la Conferencia General de la UNESCO. http://portal.unesco.org/es/ev.phpURL_ID=31058\&URL_DO=DO_TOPIC\&URL_SECTIO $\mathrm{N}=201 . \mathrm{html}$, fecha de consulta: 23 de junio de 2016.

19 Declaración Universal sobre Bioética y Derechos Humanos adoptada por la Conferencia General de la UNESCO.

${ }^{20}$ Cfr. Declaración Universal sobre Bioética y Derechos Humanos adoptada por la Conferencia General de la UNESCO. 
FERNÁNDEZ, Dora García. La violencia al inicio de la vida: una perspectiva bioética y de los derechos humanos. Revista Eletrônica Direito e Política, Programa de Pós-Graduação Stricto Sensu em Ciência Jurídica da UNIVALI, Itajaí, v.11, n.2, 2으 quadrimestre de 2016. Disponível em: www.univali.br/direitoepolitica - ISSN 1980-7791.

Por ende, los Derechos Humanos han resultado ser una gran aportación a la humanidad, pero en el campo de la Bioética estos derechos han llegado tarde y han quedado limitados al terreno de cada individuo y al respeto de sus decisiones. Pero, aunque los Derechos Humanos ya estén incluidos en el campo de la Bioética la realidad es que se siguen transgrediendo y por tanto la violencia se mantiene presente en muchos actos cometidos por el hombre contra su misma especie y su entorno.

\section{LA VIOLENCIA EN EL INICIO DE LA VIDA}

Teniendo en consideración que la vida inicia desde el momento de la concepción, podemos afirmar que desde ese momento el ser humano puede llegar a sufrir de violencia.

Se analizarán brevemente cuatro casos representativos en los que claramente se ejerce la violencia en el ser humano no nacido y en consecuencia se violan sus Derechos Humanos.

\subsection{MALTRATO FETAL}

Según una reciente investigación llevada a cabo por la psicóloga Alytia Levendosky, la violencia doméstica puede llegar a afectar a los niños incluso antes de nacer. En estos estudios se conecta el maltrato que se ejerce a una mujer embarazada con los síntomas de trauma emocional y de comportamiento de sus hijos en el primer año de vida.

La profesora Levendosky examinó la situación de 182 madres con edades entre los 18 y los 34 años y la de sus bebés, hallándose una fuerte relación 
FERNÁNDEZ, Dora García. La violencia al inicio de la vida: una perspectiva bioética y de los derechos humanos. Revista Eletrônica Direito e Política, Programa de Pós-Graduação Stricto Sensu em Ciência Jurídica da UNIVALI, Itajaí, v.11, n.2, 2으 quadrimestre de 2016. Disponível em: www.univali.br/direitoepolitica - ISSN 1980-7791.

entre los malos tratos cometidos contra una mujer embarazada por su pareja masculina y los síntomas de trauma a corta edad presentes en el hijo o hijos nacidos de ese embarazo.

Las agresiones a la mujer embarazada pueden ocasionar cambios en los sistemas de respuesta al estrés de la mujer, incrementando sus niveles de cortisol, una hormona que se libera en respuesta al estrés. Se cree que esos mayores niveles de cortisol a su vez podrían aumentar los niveles de cortisol en el feto, y que, teniendo en cuenta que el cortisol tiene efectos dañinos sobre el cerebro cuando alcanza niveles excesivos, eso podría explicar los problemas emocionales para el bebé después del nacimiento. 21

En este estudio se analiza el hecho de que la violencia doméstica sufrida por la mujer embarazada genera trastornos psicológicos en los niños incluso a una edad tan corta como la de su etapa uterina. 22

También se presenta el caso de aquellas mujeres embarazadas, generalmente adolecentes, que al no contar con el apoyo de sus padres o pareja realizan actos de violencia en contra de sí mismas, como lo es el descuido de su salud física e incluso inflingirse algún daño. Estas

${ }^{21}$ Efectos psicológicos en el bebé de la violencia doméstica a la madre durante la gestación. en http://noticiasdelaciencia.com/not/12265/efectos-psicologicos-en-elbebe-de-la-violencia-domestica-a-la-madre-durante-la-gestacion/ fecha de consulta: 1 de julio de 2016.

${ }^{22}$ Efectos psicológicos en el bebé de la violencia doméstica a la madre durante la gestación. 
FERNÁNDEZ, Dora García. La violencia al inicio de la vida: una perspectiva bioética y de los derechos humanos. Revista Eletrônica Direito e Política, Programa de Pós-Graduação Stricto Sensu em Ciência Jurídica da UNIVALI, Itajaí, v.11, n.2, 2으 quadrimestre de 2016. Disponível em: www.univali.br/direitoepolitica - ISSN 1980-7791.

conductas se consideran actos de violencia que afectan al feto, lo que se Ilama "violencia fetal" , "maltrato fetal" o "maltrato prenatal". ${ }^{23}$

De tal forma que cada acto, ya sea cometido de forma intencional o por negligencia, de manera consciente o inconsciente, que afecte al embrión o feto en alguna etapa de su desarrollo, llevada a cabo por cualquier persona que tenga injerencia en el embarazo, se define como violencia fetal.

Las consecuencias en el maltrato fetal pueden ser: retardo en el crecimiento intrauterino, prematuridad, malformaciones congénitas, muerte fetal, retraso mental, muerte súbita, entre otras.

Las formas en las que se manifiesta el maltrato fetal por parte de la mujer embarazada son, entre otras, las siguientes:

1) No acudir a recibir la adecuada atención prenatal.

2) No tener los cuidados necesarios en su estado de gravidez

3) Tener alguna adicción a sustancias nocivas

Y como ya se mencionó anteriormente, la otra forma de maltrato fetal es la violencia hacia la mujer embarazada por parte de su pareja, lo que se conoce como violencia doméstica.

${ }^{23}$ Cfr. GALICIA MOYEDA, Iris Xóchitl, et al., Relación entre maltrato fetal, violencia y sintomatología depresiva durante el embarazo de mujeres adolescentes y adultas: Un estudio piloto. en Psicología y Salud, Vol.23, Núm. 1, enero de 2013, págs. 83-95., en http://www.uv.mx/psicysalud/psicysalud-23-1/231/Iris\%20X\%C3\%B3chitl\%20Galicia\%20Moyeda.pdf, fecha de consulta 1 de julio de 2016. 
FERNÁNDEZ, Dora García. La violencia al inicio de la vida: una perspectiva bioética y de los derechos humanos. Revista Eletrônica Direito e Política, Programa de Pós-Graduação Stricto Sensu em Ciência Jurídica da UNIVALI, Itajaí, v.11, n.2, 2으 quadrimestre de 2016. Disponível em: www.univali.br/direitoepolitica - ISSN 1980-7791.

La violencia durante el embarazo afecta tanto a la mujer como al embrión o feto y por ello es un grave problema de salud pública al que hay que poner atención y ayudar a su prevención.

\subsection{ABORTO}

La palabra aborto proviene del latín abortus, que a su vez deriva del término aborior. Este concepto se utilizaba para referir a lo opuesto a orior, que es lo contrario a nacer. Por lo tanto, el aborto es la interrupción voluntaria o involuntaria del embarazo antes de que el embrión o el feto estén en condiciones de vivir fuera del vientre materno. ${ }^{24}$

Existen dos tipos de abortos: el espontáneo o natural, y el inducido. El aborto espontáneo ocurre cuando un feto se pierde por causas naturales. Las estadísticas señalan que entre el $10 \%$ y el $50 \%$ de los embarazos finalizan a causa de un aborto natural, que suele estar condicionado por la salud y la edad de la madre.

El aborto inducido, es aquel provocado con el fin de eliminar el embrión o feto, con asistencia médica o sin ella.

Según el Código Penal para el Distrito Federal, el aborto es la interrupción del embarazo después de la décima segunda semana de gestación. Para los efectos de este Código, el embarazo es la parte del proceso de la

${ }^{24}$ Cfr. Definición de aborto. en http://definicion.de/aborto/\#ixzz3JdrjKv50, fecha de consulta: 26 de junio de 2016. 
FERNÁNDEZ, Dora García. La violencia al inicio de la vida: una perspectiva bioética y de los derechos humanos. Revista Eletrônica Direito e Política, Programa de Pós-Graduação Stricto Sensu em Ciência Jurídica da UNIVALI, Itajaí, v.11, n.2, 2으 quadrimestre de 2016. Disponível em: www.univali.br/direitoepolitica - ISSN 1980-7791.

reproducción humana que comienza con la implantación del embrión en el endometrio.

El aborto inducido o provocado atenta contra la vida humana en una de sus manifestaciones importantes (la procreación) y porque el objeto de tal crimen es un ser indefenso. Es así que en la cuestión del aborto está en juego el valor intrínseco de la vida humana. El aborto es un acto en sí de violencia. Violencia ejercida en contra de la mujer pero sobretodo violencia contra el embrión, que es un ser humano que no se puede defender. El aborto es la forma más cruel de violencia pues se asesina a un ser inocente y se vulnera su derecho a la vida como derecho fundamental.

\subsection{INVESTIGACIÓN CON EMBRIONES}

La principal investigación que se realiza en embriones humanos es la obtención de células madre embrionarias para la cura de enfermedades. En 1998, el equipo de investigación del Dr. James Thomson de la Universidad de Wisconsin, publicó en una revista científica que se habían la obtenido cultivos de células madre provenientes de embriones humanos. Estas células tienen la capacidad de desarrollarse para convertirse en células especializadas y pueden regenerar células y tejidos a través de lo que se conoce como "terapias celulares". ${ }^{25}$ Enfermedades

${ }^{25}$ Cfr. THOMSON,J., Embrryonic stem cell lines deived from human blastocyst. Science, 6 november 1998, Vol. 282, No. 5391, en http://sciencemag.org, fecha de consulta: 30 de junio de 2016. 
FERNÁNDEZ, Dora García. La violencia al inicio de la vida: una perspectiva bioética y de los derechos humanos. Revista Eletrônica Direito e Política, Programa de Pós-Graduação Stricto Sensu em Ciência Jurídica da UNIVALI, Itajaí, v.11, n.2, 2으 quadrimestre de 2016. Disponível em: www.univali.br/direitoepolitica - ISSN 1980-7791.

como el Alzheimer, Parkinson, diabetes, leucemia, etcétera, podrían ser curadas con estas terapias.

Pero es importante recalcar los inconvenientes de la obtención de células madres embrionarias. En primer lugar, la investigación en embriones humanos conlleva una serie de implicaciones éticas a tomar en cuenta:

1. Se lleva a cabo en seres humanos. El embrión humano no es tan sólo vida humana potencialmente persona, sino que ya es persona actual en su ser.

2. Toda intervención técnica o biomédica en el embrión humano debe respetar su vida e integridad corpórea, por ello, sólo se debe permitir el examen genético y la terapia cuando supongan un bien sustancial para la vida y la salud del embrión con el mínimo de riesgo para éste.

3. Por lo tanto, no es aceptable la extracción de células multipotentes si con ello se destruye al embrión. . ${ }^{26}$ Porque al destruir al embrión se está ejerciendo la violencia en contra de su vida y su integridad. La destrucción en sí es un acto de violencia.

Además de las implicaciones éticas, se presentan los siguientes problemas científicos:

Primero, cuando las células madre embrionarias se trasplantan en tejidos maduros, debido a su flexibilidad y rápida proliferación generan tumores

26 Investigación con embriones humanos. en http://archiv.schoenstatt.de/news2006/01/6t0181sp-ste-dra-elena-lugo-stem-cell.php, fecha de consulta: 1 de julio de 2016. 
FERNÁNDEZ, Dora García. La violencia al inicio de la vida: una perspectiva bioética y de los derechos humanos. Revista Eletrônica Direito e Política, Programa de Pós-Graduação Stricto Sensu em Ciência Jurídica da UNIVALI, Itajaí, v.11, n.2, 2으 quadrimestre de 2016. Disponível em: www.univali.br/direitoepolitica - ISSN 1980-7791.

que pueden ser mortales si se forman en órganos vitales. Generalmente son "benignos", es decir, no cancerosos, pero estudios recientes demuestran que las células embrionarias también son genéticamente inestables y tienden a acumular mutaciones que las transforman en células cancerosas.

Segundo, las células madre embrionarias serían rechazadas por el sistema inmune del paciente, a menos que se logre una buena compatibilidad genética. A diferencia de lo que ocurre en el trasplante de órganos, las células madre se dispersan por todo el cuerpo y no pueden ser removidas en caso de rechazo. Para lograr la compatibilidad las terapias con células madre exigirían la producción intencional, y en consecuencia la destrucción de millones de embriones. ${ }^{27}$

Para resolver estos problemas podrían llevarse décadas de investigación y miles de millones de dólares, antes de alcanzar beneficios tangibles para los pacientes.

Como alternativa a esta terapia se tiene la obtención de células madre del cordón umbilical y las células madre adultas. Las células madre del cordón umbilical, que se almacenan al momento de nacer, constituyen una especie de seguro biológico y pueden ser útiles en un futuro para el bebé donante, sus padres, sus hermanos, y en otras personas con afinidad

${ }^{27}$ Cfr. CONDIC, M. Células madre y esperanza para los pacientes. en, http://www.researchgate.net/publication/242477481_Clulas_madre_y_esperanza_par a_los_pacientes, fecha de consulta: 1 de julio de 2016 . 
FERNÁNDEZ, Dora García. La violencia al inicio de la vida: una perspectiva bioética y de los derechos humanos. Revista Eletrônica Direito e Política, Programa de Pós-Graduação Stricto Sensu em Ciência Jurídica da UNIVALI, Itajaí, v.11, n.2, 2으 quadrimestre de 2016. Disponível em: www.univali.br/direitoepolitica - ISSN 1980-7791.

genética, siempre y cuando exista una compatibilidad adecuada. Además, no tienen fecha de caducidad si se guardan en nitrógeno líquido.

Las células madre adultas pueden obtenerse de muchos tejidos propios del paciente, médula ósea, tejido muscular, mucosa nasal y grasa. Recientes investigaciones han demostrado que los dientes de leche y las muelas del juicio también son fuente abundante de este tipo de células. 28

Las células procedentes de tejidos más maduros presentan muchas ventajas para su aplicación en terapias médicas, ya que no generan tumores ni son genéticamente incompatibles con el paciente. Además existen diversos estudios clínicos que demuestran su utilidad médica en enfermedades como la diabetes, esclerosis múltiple, artritis y muchos tipos de cáncer. En cambio, no ha sido aprobado ni un solo estudio clínico de células madre embrionarias por los problemas anteriormente señalados. 29

Con estas alternativas se evitaría el acto de violencia que significa hacer investigación en embriones, que aunque inmaduros, se trata de seres plenamente humanos.

\subsection{CONGELACIÓN DE EMBRIONES}

28 Células madre dentales: Promesa real de la medicina regenerativa en México. en http://www.medicable.com.mx/index.php?option=com_content\&view=article\&id $=2370$ :celulas-madre-dentales-promesa-real-de-la-medicina-regenerativa-enmexico\&catid=10\&Itemid=168, fecha de consulta 30 de junio de 2016 .

${ }^{29}$ Cfr. Células madre dentales: Promesa real de la medicina regenerativa en México.. 
FERNÁNDEZ, Dora García. La violencia al inicio de la vida: una perspectiva bioética y de los derechos humanos. Revista Eletrônica Direito e Política, Programa de Pós-Graduação Stricto Sensu em Ciência Jurídica da UNIVALI, Itajaí, v.11, n.2, 2으 quadrimestre de 2016. Disponível em: www.univali.br/direitoepolitica - ISSN 1980-7791.

A consecuencia de las técnicas de fecundación in vitro existen los llamados embriones sobrantes o supernumerarios, que son aquellos fecundados en número que excede la posibilidad de su transferencia al útero materno. Estos embriones, que no son implantados, se congelan para su conservación y futura utilización.

La forma en que se fecundan los embriones sobrantes y su excesiva acumulación, es lo que suscita una serie de consideraciones que merecen una profunda reflexión tanto ética como jurídica.

La criopreservación consiste en congelar lentamente los embriones. Este proceso requiere de un congelador de nitrógeno líquido y el uso de anticongelantes celulares. Los embriones son almacenados y sumergidos en nitrógeno líquido a $196^{\circ} \mathrm{C}$ bajo cero hasta que son descongelados y colocados en él. La conservación en frío se basa en el hecho de que las reacciones químicas (metabólicas) ocurren más lentamente a medida que desciende la temperatura. A temperaturas por debajo de los $-140^{\circ} \mathrm{C}$ se detiene toda actividad biológica. ${ }^{30}$

Es evidente que el hecho de congelar un embrión constituye un acto de violencia contra él, contra su dignidad y contra sus Derechos Humanos.

Los que defienden la criogenización de embriones argumentan que tiene como ventaja el hacer el procedimiento menos traumático para la mujer

${ }^{30}$ Cfr. GARCIA F, Dora, Dilemas éticos y jurídicos en torno a los embriones congelados, en Revista EI Mundo del Abogado. Núm. 119, Marzo de 2009, págs.. 28-30 
FERNÁNDEZ, Dora García. La violencia al inicio de la vida: una perspectiva bioética y de los derechos humanos. Revista Eletrônica Direito e Política, Programa de Pós-Graduação Stricto Sensu em Ciência Jurídica da UNIVALI, Itajaí, v.11, n.2, 2으 quadrimestre de 2016. Disponível em: www.univali.br/direitoepolitica - ISSN 1980-7791.

y por supuesto menos costoso, ya que en el caso de un fracaso, no es necesario proceder a una nueva hiperestimulación hormonal para obtener más óvulos, contando que este tratamiento hormonal es una de las etapas más caras y molestas de la FIVET. Además afirman que la congelación salva a los embriones de la destrucción al no poder ser transferidos por dificultades surgidas o por exceso de número. Pero esta salvación sólo sería auténtica si se garantizara a cada embrión la posibilidad de reiniciar su camino de diferenciación y perfeccionamiento hacia la madurez y el nacimiento. Por desgracia, el suspenso que les da la congelación frecuentemente se convierte en una especie de "antesala de la muerte", como bien lo afirma el bioeticista Maurizio Faggioni. ${ }^{31}$

Si prescindimos de este argumento de salvación para los embriones, el acto de congelarlos constituye por sí mismo un acto moralmente ilícito y violento pues lesiona la dignidad humana y los derechos que tiene el embrión de desarrollarse con esa autonomía potencial e intrínseca hacia su propio fin. Dicho de otro modo, el embrión humano es una persona y por lo tanto posee, como todo ser humano, una autonomía potencial e intrínseca, es decir, posee una autonomía desde el punto de vista ontológico más no biológico pues al igual que un bebé recién nacido el embrión depende de la madre para sobrevivir. Sin embargo, esta técnica de conservación de embriones, como ya lo establecí, trae consigo diversas implicaciones éticas. Es importante dejar claro que todo embrión humano

${ }^{31} \mathrm{Cfr}$. FAGGIONI, M., La cuestión de los embriones congelados. en http://www.bioeticaweb.com/la-cuestiasn-de-los-embriones-congelados-faggioni/ , fecha de consulta 1 de julio de 2016. 
FERNÁNDEZ, Dora García. La violencia al inicio de la vida: una perspectiva bioética y de los derechos humanos. Revista Eletrônica Direito e Política, Programa de Pós-Graduação Stricto Sensu em Ciência Jurídica da UNIVALI, Itajaí, v.11, n.2, 2으 quadrimestre de 2016. Disponível em: www.univali.br/direitoepolitica - ISSN 1980-7791.

merece el respeto propio de un individuo de la especie humana. Este respeto no deriva del afecto de sus padres ni de ninguna ley sino del hecho de ser lo que es por sí mismo, un ser humano único e irrepetible.

Además, un problema que se plantea es que la crioconservación no es del todo inofensiva para los embriones ya que aproximadamente un $40 \%$ de ellos mueren al ser descongelados y sufren irreparables daños al ser congelados. Como es de resaltarse, esta técnica implica un notable riesgo para la integridad y supervivencia de los embriones. Los embriones congelados se encuentran en un estado violento y totalmente antinatural pues se han "producido" en un laboratorio y se les ha suspendido su desarrollo vital. Por otro lado, hasta el momento se ignoran las consecuencias que a largo plazo produce esta técnica en individuos que han sido congelados en la primera etapa de su vida y que llegan a ser adultos.

Por lo tanto, no deberían existir embriones sobrantes y tampoco deberían ser congelados pues esto en definitiva, es un acto de violencia contra ellos.

\section{CONSIDERACIONES FINALES}

Como se pudo observar en estos cuatro casos aquí analizados, es justamente en la edad embrionaria donde comienza el problema de los abusos, malos tratos y violencia. Estas agresiones pueden ser ejercidas contra la mujer embarazada o directamente contra el embrión o feto, causándoles graves daños. 
FERNÁNDEZ, Dora García. La violencia al inicio de la vida: una perspectiva bioética y de los derechos humanos. Revista Eletrônica Direito e Política, Programa de Pós-Graduação Stricto Sensu em Ciência Jurídica da UNIVALI, Itajaí, v.11, n.2, 2으 quadrimestre de 2016. Disponível em: www.univali.br/direitoepolitica - ISSN 1980-7791.

No se resolverá el gran problema de la violencia si no se aprende a respetar a los seres humanos más indefensos y vulnerables. No desaparecerá el uso de la fuerza bruta como argumentación definitiva, si no se deja de maltratar al no nacido.

La Bioética es y debe ser una lucha constante y perpetua en contra de la violencia que se ejerce en el ser humano en todas sus etapas, pero sobretodo en su etapa embrionaria, y también ardua una lucha para defender, ante todo, los Derechos Humanos de los que es poseedor.

\section{REFERENCIAS DAS FONTES CITADAS}

ANDORNO, R, (2012). Bioética y dignidad de la persona, $2^{\mathrm{a}}$ ed. Tecnos, Madrid.

BASSOLS, Ramón, "Las raíces psicológicas de la violencia", en http://www.temasdepsicoanalisis.org/wp-content/uploads/2012/06/TdPN\%C2\%BA-4-R. Bassols1.pdf, fecha de consulta: 24 de junio de 2016.

"Células madre dentales: Promesa real de la medicina regenerativa en México", en

http://www.medicable.com.mx/index.php?option=com_content\&view=a rticle\&id=2370: celulas-madre-dentales-promesa-real-de-la-medicinaregenerativa-en-mexico\&catid=10\&Itemid $=168$, fecha de consulta 30 de junio de 2016.

CONDIC, M. "Células madre y esperanza para los pacientes", en, http://www.researchgate.net/publication/242477481 Clulas madre y e speranza para los pacientes, fecha de consulta: 1 de julio de 2016. 
FERNÁNDEZ, Dora García. La violencia al inicio de la vida: una perspectiva bioética y de los derechos humanos. Revista Eletrônica Direito e Política, Programa de Pós-Graduação Stricto Sensu em Ciência Jurídica da UNIVALI, Itajaí, v.11, n.2, 2으 quadrimestre de 2016. Disponível em: www.univali.br/direitoepolitica - ISSN 1980-7791.

Declaración Universal de los Derechos Humanos, en http://www.un.org/es/documents/udhr/, Fecha de consulta: 29 de junio de 2016.

Declaración Universal sobre Bioética y Derechos Humanos adoptada por la Conferencia General de la UNESCO, en

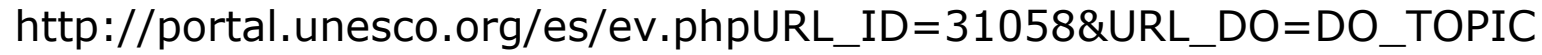
\&URL_SECTION=201.html, fecha de consulta: 23 de junio de 2016.

Definición de aborto, http://definicion.de/aborto/\#ixzz3JdrjKv50, fecha de consulta: 26 de junio de 2016.

"Efectos psicológicos en el bebé de la violencia doméstica a la madre durante la gestación", en http://noticiasdelaciencia.com/not/12265/efectos-psicologicos-en-elbebe-de-la-violencia-domestica-a-la-madre-durante-la-gestacion/ fecha de consulta: 1 de julio de 2016.

FAGGIONI, M., "La cuestión de los embriones congelados", en http://www.bioeticaweb.com/la-cuestiasn-de-los-embrionescongelados-faggioni/ , fecha de consulta 1 de julio de 2016.

GALICIA MOYEDA, Iris Xochitl, et al., "Relación entre maltrato fetal, violencia y sintomatología depresiva durante el embarazo de mujeres adolescentes y adultas: Un estudio piloto", en Psicología y Salud, Vol.23, Núm. 1, enero de 2013, págs. 83-95., en http://www.uv.mx/psicysalud/psicysalud-23-1/23-

1/Iris\%20X\%C3\%B3chitl\%20Galicia\%20Moyeda.pdf, fecha de consulta 1 de julio de 2016.

GARCIA F, Dora, "Dilemas éticos y jurídicos en torno a los embriones congelados", en Revista El Mundo del Abogado", Núm. 119, Marzo de 2009, págs.. 28-30.

"Investigación con embriones humanos", en http://archiv.schoenstatt.de/news2006/01/6t0181sp-ste-dra-elenalugo-stem-cell.php, fecha de consulta: 1 de julio de 2016. 
FERNÁNDEZ, Dora García. La violencia al inicio de la vida: una perspectiva bioética y de los derechos humanos. Revista Eletrônica Direito e Política, Programa de Pós-Graduação Stricto Sensu em Ciência Jurídica da UNIVALI, Itajaí, v.11, n.2, 2으 quadrimestre de 2016. Disponível em: www.univali.br/direitoepolitica - ISSN 1980-7791.

LOYARTE, D. y ROTONDA, A. ,(1995) Procreación humana artificial: un desafío bioético, Ediciones Depalma, Buenos Aires.

LUCAS LUCAS, R. (2008) Bioética para todos, $3^{a}$ ed., Trillas, México.

MONTOYA, Víctor, "Teorías de la violencia humana", en http://www.razonypalabra.org.mx/anteriores/n53/vmontoya.html, fecha de consulta: 29de junio de 2016.

OTERO, M. y LEOBA CASTAÑEDA, M, (Coord), (2014). Eficacia de los Derechos Humanos en el Siglo XXI. Un reto por resolver, Porrúa, México.

PÁEZ MORENO, R. "Los derechos humanos y la Bioética: una perspectiva desde Latinoamérica", en fecha http://www.bioetica.unam.mx/assets/ricardo-paez.pdf , fecha de consulta: 20 de junio de 2016.

SGRECCIA, E., (2009) Manual de Bioética, Biblioteca de Autores Cristianos, Madrid.

"Teorías sobre el origen de la violencia", en http://derechobullying.jimdo.com/t\%C3\%A9cnicas-de-

investigaci\%C3\%B3n/marco-te\%C3\%B3rico/teorias-sobre-el-origen-dela-violencia/, fecha de consulta: 29 de junio de 2016.

THOMSON,J., "Embrryonic stem cell lines deived from human blastocyst", Science, 6 november 1998, Vol. 282, No. 5391, en http://sciencemag.org, fecha de consulta: 30 de junio de 2016.

Violencia, en http://Definición de violencia - Qué es, Significado y Concepto http://definicion.de/violencia/\#ixzz4CR5TPcym, fecha de consulta 23 de junio de 2016.

Submetido em: Junho de 2016

Aprovado em: Julho de 2016. 